\title{
Evaluation on Risk of Intellectual Property Pledge Financing of Large Data Enterprises Based on Fuzzy Integral
}

\author{
Mu Zhang', Xia Feng ${ }^{1,2,3}$, Ke Zhang ${ }^{1,2,3}$ \\ ${ }^{1}$ School of Finance, Guizhou University of Finance and Economics, Guiyang 550025, China \\ ${ }^{2}$ Guizhou Institute for Urban Economics and Development, Guizhou University of Finance and \\ Economics, Guiyang 550025, China \\ ${ }^{3}$ Guizhou Institution for Technology Innovation \& Entrepreneurship Investment, Guizhou \\ University of Finance and Economics, Guiyang 550025, China
}

\section{基于模糊积分的大数据企业知识产权质押融资 风险评价 \\ 张目 ${ }^{1}$, 冯霞 ${ }^{1,2,3}$, 张珂 ${ }^{1,2,3}$ \\ 1 贵州财经大学金融学院, 贵阳 550025, 中国}

2 贵州财经大学贵州城镇经济与发展研究院, 贵阳 550025, 中国

3 贵州财经大学贵州科技创新创业投资研究院，贵阳 550025, 中国

\begin{abstract}
We try to introduce the Choquet fuzzy integral into the risk evaluation of intellectual property pledge financing of large data enterprises in this paper. Firstly, we established a risk evaluation index system of intellectual property pledge financing of large data enterprises. Secondly, according to the basic principles of fuzzy measure and Choquet fuzzy integral, we put forward an evaluation method based on Choquet fuzzy integral for the risk of intellectual property pledge financing of large data enterprises. Finally, taking a listed company in large data industry in China as sample, we used the above method to carry out an example analysis. The example analysis results show that this method can solve the
\end{abstract}

problem of risk assessment of intellectual property pledge financing of large data enterprises affected by many factors better. It is an effective multi-objective decision making method.

Keywords: Large data enterprises; Intellectual property pledge financing; Risk of intellectual property pledge financing; Fuzzy measure; Fuzzy integral

\section{摘要}

本文尝试将 Choquet 模糊积分引入到 大数据企业知识产权质押融资风险评价中。 首先, 构建大数据企业知识产权质押融资 风险评价指标体系; 然后, 根据模糊测度 和 Choquet 模糊积分的基本原理, 提出基 于 Choquet 模糊积分的大数据企业知识产 
权质押融资风险评价方法; 最后, 以大数 据产业上市公司为样本, 运用上述方法进 行实例分析。实例分析结果表明, 该方法 能够较好的解决受多因素影响的大数据企 业知识产权质押融资风险评价问题, 是一 种有效的多目标决策方法。

关键词: 大数据企业; 知识产权质押融资; 知识产权质押融资风险; 模糊测度; 模糊 积分

\section{1. 引言}

大数据产业指以数据生产、采集、存 储、加工、分析、服务为主的相关经济活 动, 包括数据资源建设、大数据软硬件产 品的开发、销售和租赁活动, 以及相关信 息技术服务。抢抓机遇, 推动大数据产业 发展, 对提升政府治理能力、优化民生公 共服务、促进经济转型和创新发展有重大 意义 (《大数据产业发展规划（2016-2020 年)》(工信部规 (2016)412 号))。国务院 在《促进大数据发展行动纲要》(国发 （2015)50 号）中提出了 “鼓励金融机构 加强和改进金融服务, 加大对大数据企业 的支持力度” 的政策意见。大数据产业属 于知识产权密集型产业, 开展知识产权质 押融资业务, 有利于拓展大数据企业融资 渠道, 加大对大数据企业的信贷支持力度。 开展知识产权质押融资业务, 需要建 立完善知识产权质押融资风险管理机制, 如何构建科学的知识产权质押融资风险评 价体系, 是建立完善知识产权质押融资风 险管理机制的基础性和关键性课题, 而知 识产权质押融资风险评价方法又是其中的 重要研究内容之一。目前, 常用的知识产 权质押融资风险评价方法主要有模糊综合 分析法 ${ }^{[1]}$ 、层次分析法 ${ }^{[2]}$ 、基于可能度的多 属性决策方法 ${ }^{[3]} 、 V I K O R$ 方法 ${ }^{[4]}$ 、BP 神经网 络 ${ }^{[5]}$ 等。上述评价方法在不同程度上都是假 定指标间相互独立, 并大多采用加法性的 方法作为评价的基础。但是在现实情况中, 评价指标的选择不可避免的出现指标间相 互关联的问题, 人的主观评价过程可能呈 现非线性特征 ${ }^{[6]}$ 。模糊积分是定义在模糊测 度基础上的一种非线性函数, 以模糊测度
作为衡量多指标重要程度的基础, 并不需 要假设指标间相互独立, 在量测方面用约 束条件较弱的单调性和连续性取代了经典 概率中的可加性 ${ }^{[7]}$, 是一种非可加法的评价 方法, 可应用于评价指标间具有相关的情 况, 适合处理主观价值判断的评价问题, 对大量的指标都可采用专家意见, 实践中 较好操作 ${ }^{[8-9]}$ 。有鉴于此, 本文尝试将 Choquet 模糊积分引入到大数据企业知识产 权质押融资风险评价中, 具体结构安排如 下: 首先, 构建大数据企业知识产权质押 融资风险评价指标体系; 然后, 根据模糊 测度和 Choquet 模糊积分的基本原理, 提 出基于 Choquet 模糊积分的大数据企业知 识产权质押融资风险评价方法; 最后, 以 大数据产业上市公司为样本, 运用上述方 法进行实例分析。

\section{2. 大数据企业知识产权质押融资风险评 价指标体系构建}

知识产权质押融资是知识产权权利人 将其合法拥有的且目前仍有效的专利权、 注册商标权、著作权等知识产权出质, 从 银行等金融机构取得资金, 并按期偿还资 金本息的一种融资方式 (《关于加强知识产 权质押融资与评估管理支持中小企业发展 的通知》(财企 [2010]199 号))。知识产权 质押融资风险包括法律风险、估值风险、 经营风险、处置风险等诸多风险。齐盼盼、 杨小哗、牛诺楠 (2012) ${ }^{[10]}$ 认为, 知识产 权质押融资风险影响因素主要包括法律因 素、知识产权因素、企业因素、银行因素、 宏观因素等五个方面。章洁倩（2013） ${ }^{[11]}$ 将科技型中小企业知识产权融资风险评价 指标确定为知识产权风险、质押管理和实 现的风险、科技型中小企业经营风险等三 个一级指标。何慧芳、刘长虹（2013） ${ }^{[1]}$ 认 为, 内部风险是指科技型企业在进行知识 产权质押融资前企业生产经营中存在的风 险, 如技术风险、生产风险、市场风险、 管理风险等; 外部风险是指知识产权质押 融资后企业由于外部不确定因素引发的风 险, 如金融风险、政策法律风险、区域的 社会风险等。邓文斌、李虹含、周凯 (2015) ${ }^{[2]}$ 提出的知识产权质押贷款风险系 
数评估指标包括法律风险、宏观环境风险、 知识产权自身风险、知识产权评估风险。 尹夏楠、鲍新中、朱莲美 (2016) ${ }^{[4]}$ 从财务 管控风险、经营管控风险、知识产权自身 风险和政府行为相关风险四个纬度构建一 套完整的知识产权质押融资企业风险的量 化指标评价体系。曾莉、王明（2016） ${ }^{[5]}$ 建 立的科技型中小企业知识产权质押融资风 险评价指标体系包括评估风险、市场风险、 生产风险、受理风险、技术风险、法律风 险、政策风险、金融风险、管理风险、区 域风险等 10 个一级指标。鲍新中、董玉环 （2016） ${ }^{[3]}$ 采用法律风险、知识产权风险、 受贷企业经营风险、银行自身风险、宏观 风险等 5 个一级指标来评价知识产权质押 融资风险。

本文根据知识产权质押融资风险的内 涵及其影响因素, 在前人研究的基础上, 结合大数据企业的发展特征 (如技术创新 能力、行业成长性等), 遵循科学性、客观 性、系统性、功能性、动态性、相对独立 性、可行性 (或可操作性) 和可比性等评 价指标的选取原则 ${ }^{[12]}$, 从企业经营风险、 知识产权风险、质押管理和变现风险等几 个方面构建了包含 3 个准则、12 个次准则 和 28 个因素的大数据企业知识产权质押融 资风险评价指标体系, 如表 1 所示。

\section{3. 模糊测度与 Choquet 模糊积分}

模糊测度与 Choquet 模糊积分的定义 用数学语言表述如下 ${ }^{[7,13-14]}$ :

定义 1 设 $X=\left(x_{1}, x_{2}, \ldots, x_{n}\right)$ 为一有限非空集 合, $P(X)$ 是 $X$ 的幕集, $t$ 是从 $P(X)$ 到 $[0,1]$ 的映射且满足: 1 ) 有界性: $f(\phi)=0, f(X)=1 ; 2)$ 单调性: $\forall A, \forall B \in P(X)$, 若 $A \subseteq B$, 则有 $f(A) \leq f(； 3)$ 连续性: $A_{n} \in P(X)$, $n=1,2, \mathrm{~L}$, 且 $\left\{A_{n}\right\}$ 为单调序列, 则有 $\lim _{n \rightarrow \infty} f\left(A_{n}\right)=f\left(\lim _{n \rightarrow \infty} A_{n}\right)$ 。则称 $f$ 为 $P(X)$ 上的模糊测度, $\left(X, A_{n}\right)$ 为模糊可测空间, $\left(X, A_{n}, f\right)$ 为模糊测度空间。
模糊测度揭示了某个 $x_{i}\left(x_{i} \in X\right)$ 属于 $X$ 子 集 $A$ 的隶属程度的度量, 对于 $x_{i}$ 与 $x_{j}\left(x_{i} \neq x_{j}\right)$ 具有这样的不等式关系:

$$
1 \geq f\left(\left\{x_{i} \neq x_{j}\right\}\right) \geq f\left(\left\{x_{i}\right\}\right) \vee f\left(\left\{x_{j}\right\}\right) 。
$$

表 1. 大数据企业知识产权质押融资风险评价指

\begin{tabular}{|c|c|c|}
\hline \multicolumn{3}{|c|}{ 标体系 } \\
\hline 准则层 & $\begin{array}{c}\text { 次准则 } \\
\text { 层 }\end{array}$ & 因素层 \\
\hline \multirow{6}{*}{$\begin{array}{l}\text { 企业经营 } \\
\text { 风险 } U_{1}\end{array}$} & $\begin{array}{l}\text { 偿 债 能 } \\
\text { 力 } U_{11}\end{array}$ & $\begin{array}{l}\text { 流动比率 } U_{111} \text {; 速动 } \\
\text { 比率 } U_{112} \text {; 资产负债 } \\
\text { 率 } U_{113}\end{array}$ \\
\hline & $\begin{array}{l}\text { 营 运 能 } \\
\text { 力 } U_{12}\end{array}$ & $\begin{array}{l}\text { 应 收 账款周 转 率 } \\
U_{121} \text {; 总资产周转率 } \\
U_{122} \text {; 存货周转率 } U_{123}\end{array}$ \\
\hline & $\begin{array}{l}\text { 盈 利 能 } \\
\text { 力 } U_{13}\end{array}$ & $\begin{array}{l}\text { 主营业务利润率 } \\
U_{131} \text {; 净资产收益率 } \\
U_{132} \text {; 总资产收益率 } \\
U_{133}\end{array}$ \\
\hline & $\begin{array}{l}\text { 成 长 能 } \\
\text { 力 } U_{14}\end{array}$ & $\begin{array}{l}\text { 净利润增长率 } U_{141} \text {; } \\
\text { 主营业务增长率 } U_{142}\end{array}$ \\
\hline & $\begin{array}{l}\text { 技 术 创 } \\
\text { 新 能 力 } \\
U_{15}\end{array}$ & $\begin{array}{l}\text { 开发支出 } U_{151} \text {; 无形 } \\
\text { 资产增长率 } U_{152} \text {; 发 } \\
\text { 明专利 申请公布数 } \\
U_{153}\end{array}$ \\
\hline & $\begin{array}{l}\text { 行业成 } \\
\text { 长性 } U_{16}\end{array}$ & $\begin{array}{l}\text { 行业平均营业收入增 } \\
\text { 长率 } U_{161}\end{array}$ \\
\hline \multirow{3}{*}{$\begin{array}{l}\text { 知识产权 } \\
\text { 风险 } U_{2}\end{array}$} & $\begin{array}{l}\text { 知 识产 } \\
\text { 权 管 理 } \\
\text { 水平 } U_{21}\end{array}$ & $\begin{array}{l}\text { 知识产权风险防范意 } \\
\text { 识 } U_{211} \text {; 知识产权法 } \\
\text { 律事务管理的规范性 } \\
U_{212}\end{array}$ \\
\hline & $\begin{array}{l}\text { 知 识产 } \\
\text { 权权属 } \\
U_{22} \\
\end{array}$ & $\begin{array}{l}\text { 所有权 是 否 清 晰 } \\
U_{221} \text {; 是否存在重复担 } \\
\text { 保 } U_{222}\end{array}$ \\
\hline & $\begin{array}{l}\text { 知 识产 } \\
\text { 权 保护 } \\
U_{23}\end{array}$ & $\begin{array}{l}\text { 有效期及地域的限制 } \\
U_{231} \text {; 知识产权的技术 } \\
\text { 含量 } U_{232} \text {; 知识产权 } \\
\text { 被侵权的可能性 } U_{233}\end{array}$ \\
\hline \multirow{3}{*}{$\begin{array}{l}\text { 质押管理 } \\
\text { 和变现风 } \\
\text { 险 } U_{3}\end{array}$} & $\begin{array}{l}\text { 知 识产 } \\
\text { 权估值 } \\
\text { 风险 } U_{31}\end{array}$ & $\begin{array}{l}\text { 评估机构的资质及信 } \\
\text { 誉 } U_{311} \text { ；评估方法的 } \\
\text { 科学合理性 } U_{312}\end{array}$ \\
\hline & $\begin{array}{l}\text { 担 保安 } \\
\text { 排 } U_{32}\end{array}$ & 质押率 $U_{321}$ \\
\hline & $\begin{array}{l}\text { 知 识产 } \\
\text { 权变现 } \\
\text { 风险 } U_{33}\end{array}$ & $\begin{array}{l}\text { 知识产权价值的稳定 } \\
\text { 性 } U_{331} \text {; 知识产权的 } \\
\text { 可转让性 } U_{332} \text {; 知识 } \\
\text { 产权交易市场完善程 } \\
\text { 度 } U_{333}\end{array}$ \\
\hline
\end{tabular}

定义 2 对于所有的 $A, B \in P(X)$, 且 $A \mathrm{I} B=\Phi, \lambda \in[-1,+\infty)$, 若模糊测度 $f_{\lambda}$ 
满足如下条件:

$$
f_{\lambda}(A \mathrm{U} B)=f_{\lambda}(A)+f_{\lambda}(B)+\lambda f_{\lambda}(A) f_{\lambda}(B)
$$

则称 $f_{\lambda}$ 为 $\lambda$ 的模糊测度。

通常情况下, 模糊测度不具有可加性。

对只有单一元素 $x_{i}$ 的子集合, 其 $f\left(\left\{x_{i}\right\}\right)$ 称为模 糊 密度, 若 $X=\left(x_{1}, x_{2}, \mathrm{~L}, x_{n}\right)$ 为有限非空集合, 且各变 量 $x_{i}$ 的模糊密度函数为 $f\left(x_{i}\right)$, 则 $f_{\lambda}$ 具有 如下性质:

$$
f_{\lambda}\left(A_{i}\right)=\frac{1}{\lambda}\left\lfloor\prod_{i=1}^{n}\left(1+\lambda f_{i}\right)-1\right\rfloor
$$

而 $\lambda \in[-1,+\infty)$, 当 $f(X)=1$ 时, 上式可 以简化为:

$$
\lambda+1=\prod_{i=1}^{n}\left(1+\lambda f_{i}\right)
$$

定义 3 设 $(X, P(X), f)$ 为一个模糊测度 空间, $h: X \rightarrow[0,1]$ 是 $X$ 上的可测函数, $A \in P(X)$ 。则 $h$ 在 $A$ 上关于模糊测度 $\nmid$ 的 Choquet 模糊积分定义为:

$$
H=\int_{x} h(x) f(\bullet)=\sum_{i=1}^{n}\left[h\left(x_{i}\right)-h\left(x_{i-1}\right)\right] f\left(h_{i}\right)
$$

其中, $f(\cdot)$ 表示某集合的测度。

\section{4. 基于 Choquet 模糊积分的大数据企业 知识产权质押融资风险评价方法}

\section{1 语意变量与三角模糊数}

语意变量是以人类的自然语言中的语 词为值, 而不是以数据为值。指标表现语 意变量取 7 个等级 ${ }^{[15]}$ : 非常差、差、较差、 一般、较好、好、非常好; 指标权重语意 变量取 5 个等级 ${ }^{[6]}$ : 很不重要、不重要、普 通、重要、很重要。语意变量与三角模糊 数的对应关系如表 2 所示。

\section{2 基于 Choquet 模糊积分的大数据企业 知识产权质押融资风险评价步骤}

设有待评价的大数据企业 A, 同时考虑 $\mathrm{n}$ 个评价准则, 且每个评价准则有若干个评
价因素, 则大数据企业知识产权质押融资 风险评价的具体步骤为:

步骤 1: 针对待评价的大数据企业 $\mathrm{A}$ 在 表 2. 语意变量与三角模糊数的对应关系

\begin{tabular}{|c|c|c|c|}
\hline $\begin{array}{c}\text { 指标表现 } \\
\text { 语意变量 }\end{array}$ & $\begin{array}{c}\text { 三角模糊 } \\
\text { 数 }\end{array}$ & $\begin{array}{c}\text { 指标权重 } \\
\text { 语意变量 }\end{array}$ & $\begin{array}{c}\text { 三角模糊 } \\
\text { 数 }\end{array}$ \\
\hline 非常差 & $(0,0,0.1)$ & 很不重要 & $(0,0$, \\
& & & $0.25)$ \\
\hline 差 & $\begin{array}{c}(0,0.1, \\
0.3)\end{array}$ & 不重要 & $(0,0.25$, \\
& & $0.5)$ \\
\hline 较差 & $\begin{array}{c}(0.1,0.3, \\
0.5)\end{array}$ & 普通 & $\begin{array}{c}(0.25,0.5, \\
0.75)\end{array}$ \\
\hline 一般 & $\begin{array}{c}(0.3,0.5, \\
0.7)\end{array}$ & 重要 & $\begin{array}{c}(0.5,0.75, \\
1.0)\end{array}$ \\
\hline 较好 & $\begin{array}{c}(0.5,0.7, \\
\end{array}$ & 很重要 & $\begin{array}{c}(0.75,1.0, \\
1.0)\end{array}$ \\
\hline 好 & $(0.9)$ & & - \\
\hline 非常好 & $0.9,1)$ & & - \\
\hline
\end{tabular}

各评价准则下的每个评价因素, 由 $K$ 位专 家分别给出指标权重语意变量和指标表现 语意变量。

步骤 2: 由表 2 , 将语意变量转换为三角模 糊数。综合 $\mathrm{K}$ 位专家意见 ${ }^{[16]}$, 得出待评价 的大数据企业 $\mathrm{A}$ 在第 $i$ 个评价准则下第 $k$ $\left(k=1,2, \mathrm{~L}, l_{i}\right)$ 个评价因素的指标表现模 糊值 $\tilde{X}_{i k}$ 和指标权重模糊值 $\widetilde{W}_{i k}$, 待评价的大 数据企业 $\mathrm{A}$ 在第 $i$ 个评价准则下的模糊评价 值为:

$\tilde{X}_{i}=\left(\tilde{X}_{i 1} \otimes \widetilde{W}_{i 1} \oplus \tilde{X}_{i 2} \otimes \widetilde{W}_{i 2} \oplus \cdots \oplus \tilde{X}_{i l_{i}} \otimes\right.$ $\left.\widetilde{W}_{i l_{i}}\right) / l_{i}$

其中, $l_{i}$ 为第 $i$ 个评价准则下评价因素的个 数。

步骤 3: 利用模糊数相对距离公式 ${ }^{[17]}$

$$
\frac{\sqrt{\left(a^{2}+b^{2}+c^{2}\right) / 3}}{\sqrt{\left(a^{2}+b^{2}+c^{2}\right) / 3}+\sqrt{\left[(1-a)^{2}+(1-b)^{2}+(1-c)^{2}\right] / 3}}
$$

将模糊评价值 $\tilde{X}_{i}$ 解模糊化为明确值 $\bar{X}_{i}$ 。

步骤 4 : 综合第 $i$ 个评价准则下 $l_{i}$ 个评 价因素的指标权重模糊值 $\widetilde{W}_{i k}$, 获得第 $i$ 个 评价准则的模糊权重值 $\widetilde{W}_{i}{ }^{[16]}$ 。利用模糊数 相对距离公式, 将模糊权重值 $\widetilde{W}_{i}$ 解模糊化 为明确值 $\bar{W}_{i}$ 。

步骤 5 : 将模糊权重值 $\widetilde{W}_{i}$ 解模糊化为 
明确值 $\bar{W}_{i}$, 将 $\bar{W}_{i}$ 以 $f_{i}$ 表示, 并代入式 (3), 通过试算求解出 $\lambda$ 的近似值。

步骤 6: 将模糊评价值 $\tilde{X}_{i}$ 解模糊化为明 确值 $\bar{X}_{i}$, 将 $\bar{X}_{i} \quad(i=1,2, \ldots, n)$ 按从小到大重 新排序。

步骤 7 : 根据求解出的 $\lambda$ 的近似值和 $f_{i}$ 值, 利用式 (2) 分别求出各个评价准则的 $\lambda$-模糊测度 $f_{\lambda}$ 。

步骤 8: 将明确值 $\bar{X}_{i}$ 与求出的 $\lambda$-模糊 测度 $f_{\lambda}$ 代入式 (4), 求出待评价的大数据 企业 A 的 Choquet 模糊积分值 $H_{A}$, $H_{A} \in[0,1], H_{A}$ 越大, 知识产权质押融资 风险越低。

\section{5. 实例分析}

\section{1 样本数据}

本文参照文献 ${ }^{[4]}$, 选取创业板中的大数 据产业上市公司一一网宿科技 (300017) 为研究样本。该公司所属证监会行业为: 信息传输、软件和信息技术服务业-软件和 信息技术服务业, 主要业务是向客户提供 全球范围内的内容分发与加速 (CDN) 服务、 互联网数据中心 (IDC) 服务及云服务整体解 决方案, 因此, 符合大数据产业发展方向。 本文将样本区间设定为 2016 年, 原始数据 见表 3。其中, 在企业经营风险的因素指标 中, 发明专利申请公布数指标数据来源于 天眼查网站, 其余指标数据均来源于东方 财富网站; 知识产权风险、质押管理和变 现风险的因素指标数据均由专家语意给出。

\subsection{Choquet 模糊积分计算}

(1) 计算第 $i$ 个评价准则的模糊权重值 $\widetilde{W}_{i}$ 及其明确值 $\bar{W}_{i}$ 。综合 3 位专家意见, 得出 样本企业在第 $i$ 个评价准则下第 $k$ $\left(k=1,2, \mathrm{~L}, l_{i}\right)$ 个评价因素的指标权重模 糊值 $\widetilde{W}_{i k}$ 。综合第 $i$ 个评价准则下 $l_{i}$ 个评价 因素的指标权重模糊值 $\widetilde{W}_{i k}$, 获得第 $i$ 个评

\begin{tabular}{|c|c|c|c|}
\hline 因素指标 & $\begin{array}{c}\text { 指标 } \\
\text { 值 } \\
\end{array}$ & 因素指标 & $\begin{array}{c}\text { 指标 } \\
\text { 值 } \\
\end{array}$ \\
\hline 流动比率 & 6.73 & $\begin{array}{l}\text { 总资产收益 } \\
\text { 率 }(\%)\end{array}$ & 20.52 \\
\hline 速动比率 & 6.49 & $\begin{array}{l}\text { 净利润增长 } \\
\text { 率 }(\%)\end{array}$ & 50.52 \\
\hline $\begin{array}{l}\text { 资产负债率 } \\
(\%)\end{array}$ & 15.08 & $\begin{array}{l}\text { 主营业务增 } \\
\text { 长率 }(\%)\end{array}$ & 51.67 \\
\hline $\begin{array}{l}\text { 应收账款周 } \\
\text { 转率 (次) }\end{array}$ & 5.48 & $\begin{array}{l}\begin{array}{l}\text { 开 发 支 出 } \\
\text { (万元) }\end{array} \\
\end{array}$ & 5605 \\
\hline $\begin{array}{l}\text { 总资产周转 } \\
\text { 率 (次) }\end{array}$ & 0.73 & $\begin{array}{l}\text { 无形资产增 } \\
\text { 长率 }(\%)\end{array}$ & 60.57 \\
\hline $\begin{array}{l}\text { 存货周转率 } \\
\text { (次) }\end{array}$ & 17.32 & $\begin{array}{l}\text { 发明专利申 } \\
\text { 请 公 布 数 } \\
\text { (件) }\end{array}$ & 83 \\
\hline $\begin{array}{l}\text { 主营业务利 } \\
\text { 润率 (\%) }\end{array}$ & 28.07 & $\begin{array}{l}\text { 行业平均营 } \\
\text { 业收入增长 } \\
\text { 率 }(\%)\end{array}$ & 23.06 \\
\hline $\begin{array}{l}\text { 净资产收益 } \\
\text { 率 }(\%)\end{array}$ & 17.08 & $\ldots \ldots$ & \\
\hline
\end{tabular}

价准则的模糊权重值 $\widetilde{W}_{i}$ :

$$
\widetilde{W}_{1}=(0.5833,0.8333,0.9583)
$$

解模糊化得: $\bar{W}_{1}=0.7561$ 。同理可得:

$\widetilde{W}_{2}=(0.5833,0.8333,0.9167), \quad \bar{W}_{2}=0.7500$

$\widetilde{W}_{3}=(0.6667,0.9167,1.0000), \quad \bar{W}_{3}=0.8148$

(2) 求解 $\lambda$ 的近似值。将上述解模糊 化得到的明确值 $\bar{W}_{i}$ 以 $f_{i}$ 表示, 代入式 (3), 求得 $\lambda \approx-0.9874$ 。

(3) 计算第 $i$ 个评价准则下的模糊评 价值 $\mathscr{X}_{i}^{0}$ 及其明确值 $\bar{X}_{i}$ 。综合 3 位专家意见, 得出样本企业在第 $i$ 个评价准则下第 $k$ $\left(k=1,2, \ldots, l_{i}\right)$ 个评价因素的指标表现模糊 值 $\tilde{X}_{i k}$ 。由式 (5) 计算得出样本企业在第 $i$ 个评价准则下的模糊评价值 $\tilde{X}_{i}$ :

$$
\tilde{X}_{1}=(0.3306,0.6511,0.8456)
$$

解模糊化得: $\bar{X}_{1}=0.5918$ 。同理可得: $\tilde{X}_{2}=(0.3810,0.7286,0.8875), \quad \bar{X}_{2}=0.6381$ $\tilde{X}_{3}=(0.3111,0.6083,0.8389), \quad \bar{X}_{3}=0.5723$

(4) 将 $\bar{X}_{i} \quad(i=1,2, \ldots, n)$ 按从小到大 重新排序: $\bar{X}_{3}<\bar{X}_{1}<\bar{X}_{2}$, 相应记为: 


$$
\bar{X}_{1}^{\prime}<\bar{X}_{2}^{\prime}<\bar{X}_{3}^{\prime}
$$

(5) 计算 $\lambda$-模糊测度 $f_{\lambda}$ 。根据求解 出的 $\lambda$ 的近似值和 $f_{i}$ 值, 利用式 (2) 分别 求出各个评价准则的 $\lambda$-模糊测度 $f_{\lambda}$ :

$$
\begin{aligned}
& f_{\lambda}\left(\bar{X}_{3}\right)=0.8148 \\
& f_{\lambda}\left(\bar{X}_{3}, \bar{X}_{1}\right)= 0.8148+0.7561+(-0.9874) \times 0.8148 \\
& \times 0.7561=0.9626 \\
& f_{\lambda}\left(\bar{X}_{3}, \bar{X}_{1}, \bar{X}_{2}\right)=0.9626+0.7500+(-0.9874) \times 0.9626 \\
& \times 0.7500=0.9997
\end{aligned}
$$

(6) 计算 Choquet 模糊积分值 $H_{A}$ :

$H_{A}=0.9997 \times 0.5723+0.9626 \times(0.5918-0.5723)$

$$
+0.8148 \times(0.6381-0.5918)=0.6286
$$

Choquet 模糊积分值为 0.6286 , 表明样本 企业的知识产权质押融资风险相对较低。

\section{6. 结束语}

本文根据模糊测度和 Choquet 模糊积 分的基本原理, 在 $\lambda$-模糊测度的基础上, 引 $\lambda$ Choquet 模糊积分, 提出了基于 Choquet 模糊积分的大数据企业知识产权质 押融资风险评价方法; 并构建大数据企业 知识产权质押融资风险评价指标体系, 以 大数据产业上市公司为样本, 运用该方法 进行了实例分析。实例分析结果表明, 该 方法能够较好的解决受多因素影响的大数 据企业知识产权质押融资风险评价问题, 是一种有效的多目标决策方法。模糊测度 有多种具有特殊构造的类型, 如可能性测 度、必要性测度、信任测度、 $\lambda$-模糊测度 等, 运用不同的模糊测度类型进行比较分 析, 值得进一步探讨。

\section{致谢}

本研究得到了国家自然科学基金地区项目 《贷款风险补偿资金对科技型中小企业信 贷配给的影响机理研究》（71263011）、 2017 年度第二批贵州省基础研究计划（软 科学类别) 项目《贵州大数据产业、生态 文明建设与金融集聚耦合协调发展研究》 (黔科合基础 (2017) 1516-1) 的资助。

\section{参考文献}

[1] 何慧芳,刘长虹. 基于模糊综合分析法的 广东省知识产权质押融资的风险预警 评价研究.科技管理研究,2013,33(14): 1 51-155+159.

[2] 邓文斌, 李虹含, 周凯. 商业银行知识产权 质押贷款风险评估一一基于 $\mathrm{A}$ 出版企 业的实证研究.南方金融,2015,(5):77-83.

[3] 鲍新中,董玉环.知识产权质押融资风险 评价研究——基于银行视角. 南京审计 学院学报,2016,13(2):48-56.

[4] 尹夏楠,鲍新中,朱莲美. 基于融资主体视 角的知识产权质押融资风险评价研究. 科技管理研究,2016,36(12):125-129.

[5] 曾莉,王明.基于 BP 神经网络的科技型 中小企业知识产权质押融资风险评价. 科技管理研究,2016,36(23):164-167.

[6] 张朝勇,王卓甫,邢会歌. 基于 Choquet 模 糊积分的工程投标风险评估方法.土木 工程学报,2007,40(10):98-104.

[7] 哈明虎, 吴从炘. 模糊测度与模糊积分理 论.北京:科学出版社, 1998 .

[8] 张群, 李岭, 邵球军, 来守林. 模糊积分在 多目标决策中的应用研究. 管理学报, 20 07,(4):390-392.

[9] 许永平,朱延广, 杨峰,王维平. 基于 ANP 和模糊积分的多准则决策方法及其应 用.系统工程理论与实践,2010,30(6): 10 99-1105.

[10] 齐盼盼, 杨小晔,牛诺楠.知识产权质押融 资风险评价模型研究.会计之友,2012, (2 5):102-105.

[11] 章洁倩.科技型中小企业知识产权质押 融资风险管理——基于银行角度.科学 管理研究,2013,31(2):98-101.

[12] Zhang M, Zhou Z F. A credit rating model for enterprises based on projection pursuit and k-means clustering algorithm. Journal of Risk Analysis and Crisis Response, 2012, 2(2): 131-138.

[13] Sugeno M. Theory of fuzzy integrals and its application. Tokyo: Tokyo Institute of Technology, 1974. 
[14] Murofushi T, Sugeno M. An interpretation of fuzzy measures and the Choquet integral as an integral with respect to a fuzzy measure. Fuzzy Sets and Systems, 1989,29(2):201-227.

[15] 王娟茹.基于模糊 AHP 和 TOPSIS 的企 业知识吸收能力评价.工业工程,2010,13 (3):105-110.

[16] 刘颖,王国红,陈大鹏.基于模糊积分的集 群产业集成度测度与评价一一以大连 软件产业集群为例.科学学与科学技术 管理,2010,31(12):86-90.

[17] 李士勇.工程模糊数学及应用.哈尔滨: 哈 尔滨工业大学出版社,2004. 